\title{
A Case of Long-Term Maintenance ECT in a 78-Year- Old with Depression and Possible Parkinson's Disease
}

\section{To the Editor:}

February 21, 2007

Electroconvulsive therapy (ECT) is a wellestablished treatment modality in psychiatry. However, much concern has been raised about the possible cognitive effects of long-term ECT.

This case report concerns a 78-year-old woman with depression and Parkinson's-like symptoms who has continued to receive maintenance ECT for 6 years with intact cognitive status.

ECT is an efficacious treatment option for major depression, especially with melancholic features, cases that are medication resistant or are acutely suicidal, and those with associated psychotic features. There is also sufficient data ${ }^{1}$ to suggest that ECT helps in movement disorders, especially Parkinson's disease.

Here we report a case of Ms. J, a 78-yearold single black woman with a long-standing history of major depression, recurrent with psychotic features. Ms. J has been receiving long-term maintenance ECT (6 years duration), initially monthly, but in order to maintain complete remission and euthymia, she has required biweekly treatments for over 1.5 years.

Ms. J has a past psychiatric history significant for several psychiatric hospitalizations and suicide attempts by overdose. Up until early 2000 , she had been relatively stable on a combination of fluoxetine $20 \mathrm{mg} /$ day and thiothixene $8 \mathrm{mg} /$ day without significant extrapyramidal symptoms. She developed medication resistance in late 2000 and received an acute course of ECT, followed by continuation and maintenance ECT. She continues to receive such treat- ments to date. When euthymic, Ms. $J$ is usually neatly dressed, has no gross psychomotor abnormality, is bright, cheerful, and interactive with a fairly preserved cognitive status. Her Mini-Mental Status Exam scores usually range between $25 / 30$ and $28 / 30$. However, in the rare instance that she does not receive ECT at the requisite frequency, she shows a rapid decline not only in terms of mood and appearance of psychotic symptoms, but also in her gait, cognition, and appearance of pseudoparkinsonian symptoms, such as rigidity, mask-like faces, and tremors. Over the years, successful maintenance ECT has not only helped her to continue to live independently, it has preserved her mental status as well.

This case highlights several points. First, it reiterates that for some resistant cases longterm maintenance ECT may be the only successful treatment option.

Second, cognitive impairment is not necessarily a consequence of long-term maintenance ECT. ${ }^{2}$ In this case, maintenance ECT has improved the patient's cognition throughout acute episodes of depression, and has enabled her to live independently as opposed to being committed to a state hospital or group home for the rest of her life.

Lastly, we suggest that this might be a case of long-term maintenance ECT not only for depression but also for parkinsonism. It has been difficult to clearly delineate whether or not this patient's motor symptoms are a state related feature or symptoms of true Parkinson's disease, as mood and neurologi- 


\title{
Communique
}

cal symptoms decline and remit simultaneously. There is evidence in the literature that suggests an acute course of ECT is beneficial for the motor symptoms in patients with parkinsonism with depression. ${ }^{3}$ However, there is a paucity of literature regarding long-term maintenance ECT and simultaneous monitoring of cognition.

It would certainly be worth having randomized controlled studies evaluating the benefits of maintenance ECT in patients with depression and concomitant motor symptoms.

Sincerely,

L. Douglas Balke, MD

Anjali Varma, MD

\section{REFERENCES}

1. Fall PA, Granérus AK. Maintenance ECT in parkinson's disease. J Neural Transm. 1999:106:737-741.

2. Vothknecht $\mathrm{S}$, Kho KH, van Schaick $H W$, et al. Effects of maintenance electroconvulsive therapy on cognitive functions. JECT. 2003:19:151-157.

3. Moellentine $\mathrm{C}_{2}$ Rummans $T$, Ahlskog JE, et al. Effectiveness of ECT in patients with parkinsonism. J Neuropsychiatry Clin Neurosci. 1998; 10:187-193.

Dr. Balke is assistant clinical professor and Dr. Varma is PGY3. resident, both in the Department of Psychiatry at the University of Virginia School of Medicine, Carilion Roanoke Salem Program, Carilion Roanoke Memorial Hospital, in Roanoke.

Disclosure: Dr. Balke and Dr. Varma report no affiliation with or finanical interest in an organization that may pose a conflict of interest.

Please send letters to the editor to: CNS Spectrums, c/o Eric Hollander, MD, 333 Hudson St., 7th Floor, New York, NY 10013; E-mail: vi@mblcommunications.com.

\section{Now Available Free Online at www.cnsspectrums.com CME-ACCREDITED SUPPLEMENT CME 1}

An expert review of clinical challenges in psychiatry and neurology

\section{Recent Advances in the Treatment and Management of Excessive Daytime Sleepiness}

\author{
by Jed Black, MD, Stephen P. Duntley, MD, \\ Richard K. Bogan, MD, FCCP, and Mary B. O'Malley, MD, PhD \\ To request a published supplement, pleasee-mail ks@mblcommunications.com \\ Supported by an educational grant from Jazz Pharmaceuticals.
}

